\title{
An improved semi-empirical model for the densification of Antarctic firn
}

\author{
S. R. M. Ligtenberg, M. M. Helsen, and M. R. van den Broeke \\ Institute for Marine and Atmospheric research Utrecht (IMAU) P.O. Box 80000, 3508 TA Utrecht, The Netherlands
}

Received: 10 June 2011 - Published in The Cryosphere Discuss.: 21 July 2011

Revised: 26 September 2011 - Accepted: 27 September 2011 - Published: 12 October 2011

\begin{abstract}
A firn densification model is presented that simulates steady-state Antarctic firn density profiles, as well as the temporal evolution of firn density and surface height. The model uses an improved firn densification expression that is tuned to fit depth-density observations. Liquid water processes (meltwater percolation, retention and refreezing) are also included. Two applications are presented. First, the steady-state model version is used to simulate the strong spatial variability in firn layer thickness across the Antarctic ice sheet. Second, the time-dependent model is run for 3 Antarctic locations with different climate conditions. Surface height changes are caused by a combination of accumulation, melting and firn densification processes. On all 3 locations, an upward trend of the surface during autumn, winter and spring is present, while during summer there is a more rapid lowering of the surface. Accumulation and (if present) melt introduce large inter-annual variability in surface height trends, possibly hiding ice dynamical thickening and thinning.
\end{abstract}

\section{Introduction}

The Antarctic ice sheet (AIS) is almost entirely covered by a layer of firn, the intermediate product in the transition from snow to ice. In Antarctica, fresh snow has a typical density of $350 \mathrm{~kg} \mathrm{~m}^{-3}$, while glacier ice has a density of more than $900 \mathrm{~kg} \mathrm{~m}^{-3}$. At low temperatures and accumulation rates, densification of firn is a slow process and the transition can take up to centuries or millennia. The large range of surface climate conditions in Antarctica introduces widely varying characteristics of the firn layer in space and time $(\mathrm{Li}$ and Zwally, 2004; van den Broeke, 2008; and Helsen et al., 2008). For instance, the firn layer thickness can vary between

Correspondence to: S. R. M. Ligtenberg (s.r.m.ligtenberg@uu.nl) a few tens of meters in the relatively warm coastal areas to $>100 \mathrm{~m}$ in the cold interior of East Antarctica. In ablation areas, where sublimation, snowdrift erosion and/or melt exceed snowfall, the firn layer can even be completely absent, resulting in formation of blue ice areas (Winther et al., 2001).

The steady and transient states of the firn layer provide important information on firn air content and surface elevation changes. These are crucial parameters needed to estimate the contemporary mass balance of the AIS using remotesensing techniques (Rignot et al., 2008; Helsen et al., 2008; van den Broeke et al., 2008). Figure 1, adjusted from Zwally and $\mathrm{Li}$ (2002), shows the various components of the vertical displacement of the ice sheet surface. A change in surface height with time $(d H / d t)$ is given as the sum of these velocity components:

$$
\frac{d H}{d t}=v_{\mathrm{acc}}+v_{\mathrm{me}}+v_{\mathrm{fc}}+v_{\text {ice }}+v_{\mathrm{b}}
$$

where $v_{\mathrm{acc}}, v_{\mathrm{me}}, v_{\mathrm{fc}}, v_{\text {ice }}$ and $v_{\mathrm{b}}$ are the velocity components that represent accumulation, melt, firn compaction, ice flow and bedrock movement, respectively. Since we focus on relative short timescales, $v_{\mathrm{b}}$ is negligible and $v_{\text {ice }}$ is assumed proportional to the average annual accumulation. The effect of sublimation is included in the accumulation velocity, $v_{\text {acc. }}$. These velocity components can be combined in time-dependent firn densification models to calculate temporal changes in firn depth and density and surface height changes, by forcing them with time series of surface temperature, snowfall, sublimation and melt. These results can be used to convert satellite elevation change measurements to mass changes (Davis et al. (2005) and Wingham et al. (2009) among others). It has been demonstrated that variability in firn densification rate and accumulation strongly influence the observed surface height changes (McConnell et al., 2000; Helsen et al., 2008).

Published by Copernicus Publications on behalf of the European Geosciences Union. 


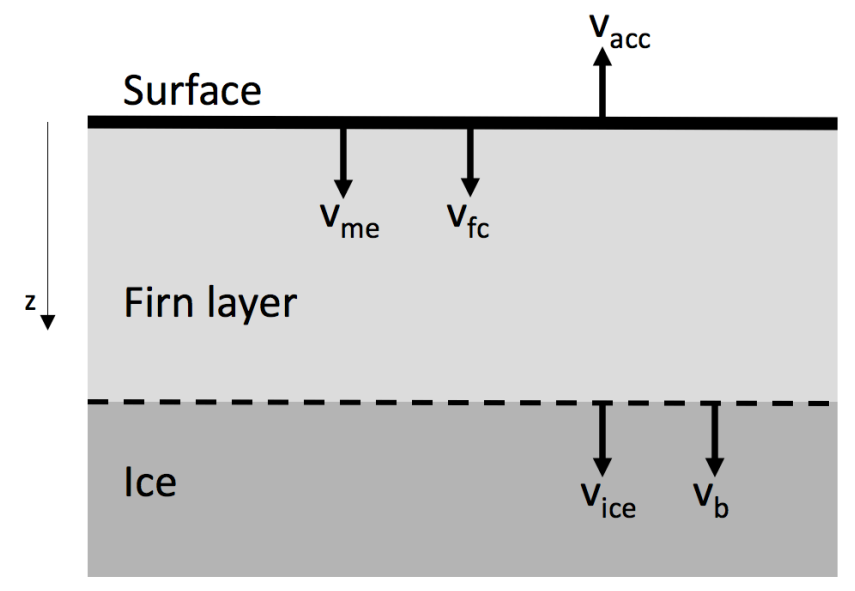

Fig. 1: Schematic representation of the firn layer (including surface snow) and the velocity components contributing to surface elevation changes: accumulation $\left(v_{\text {acc }}\right)$, melt $\left(v_{\text {me }}\right)$, firn compaction $\left(v_{\mathrm{fc}}\right)$, downward ice flow $\left(v_{\text {ice }}\right)$ and bedrock movement $\left(v_{\mathrm{b}}\right)$, adjusted from Zwally and Li (2002).

Several models have been proposed to describe firn densification. Some are based on physical principles (for example Wilkinson, 1988), while others use semi-empirical parameterizations (Herron and Langway (1980); Barnola et al. (1991); Helsen et al. (2008), and Arthern et al., 2010). A distinction can also be made between models that describe the steady-state density profile, and models that simulate changes in the firn layer over time. Steady-state firn profiles can be used to estimate the amount of air in the firn column, which is used to convert ice thicknesses to total mass of an ice column. van den Broeke (2008) showed that the steady-state solution of Barnola et al. (1991), forced with regional atmospheric climate model output from van de Berg et al. (2006), is in good agreement with observations from firn cores. For the upper layers, this model uses the semi-empirical steadystate solution of Herron and Langway (1980), while for the lower part the equations of Pimienta and Duval (1987) are used. Recent expressions for time-dependent firn densification and depth are those of Helsen et al. (2008) and Arthern et al. (2010), which are both based on the model of Herron and Langway (1980). The latter assumes that firn compaction has an Arrhenius-type temperature sensitivity and was tuned to fit steady-state density profiles from Greenland and Antarctica. A different temperature sensitivity was added by Li and Zwally (2004), which was later modified by Helsen et al. (2008) to make it suitable for Antarctica. None of these models included snow melt and refreezing, while it is well known that the higher density of refrozen melt water can have a significant effect on the density of the firn column and its densification rate.

In this paper we present a firn densification model (FDM) that calculates steady-state as well as time-dependent firn density profiles for Antarctica. The advantage of this model is that it uses the same densification expression for both purposes, tuned to optimally fit observations. Also snow melt and percolation, retention and refreezing of meltwater is implemented. In Sect. 2, we describe the model and its forcing. In Sect. 3, two applications are presented; first, we present an update of the characteristics and spatial variability of the steady-state Antarctic firn layer. Next, we present time series of surface height changes at various locations across Antarctica. For both applications, the FDM is forced with output of the regional atmospheric climate model RACMO2/ANT (Lenaerts et al., 2011a).

\section{Methods}

\subsection{Atmospheric forcing}

The FDM is forced at the surface by the surface mass balance, surface temperature and near-surface wind speed from the regional atmospheric climate model RACMO2/ANT. Model data is available for the period 1979-2009 at a temporal resolution of $6 \mathrm{~h}$ and a horizontal resolution of $27 \mathrm{~km}$. RACMO2/ANT is forced at the lateral boundaries with ERAInterim re-analysis data, which also provides the sea ice cover and sea surface temperatures. The average annual accumulation, as used in this paper, is the sum of solid and liquid precipitation minus sublimation. The climate and surface mass balance of RACMO2/ANT has been validated by Lenaerts et al. (2011b); Lenaerts and van den Broeke (2011) and Kuipers Munneke et al. (2011) and is shown to provide a good representation of the Antarctic near-surface climate.

\subsection{Firn densification model}

Our FDM is a time-dependent one-dimensional model that keeps track of the density and temperature in a vertical firn column. New added surface snow is instantly treated as the upper layer of the vertical firn column. The fresh snow density for each grid point is determined by a parameterization of Kaspers et al. (2004), based on average annual accumulation $\left(\dot{b}\right.$ in mm w.e. $\left.\mathrm{yr}^{-1}\right), 10 \mathrm{~m}$ wind speed $\left(\overline{V_{10}}\right.$ in $\left.\mathrm{m} \mathrm{s}^{-1}\right)$ and surface temperature $\left(\bar{T}_{s}\right.$ in $\left.\mathrm{K}\right)$, with a slope correction for Antarctica by Helsen et al. (2008):

$\rho_{\mathrm{s}}=-151.94+1.4266\left(73.6+1.06 \bar{T}_{\mathrm{s}}+0.0669 \dot{b}+4.77 \overline{V_{10}}\right)$

The previous time-dependent model version (Helsen et al., 2008) did not consider processes associated with liquid water: rain, snow melt, percolation and refreezing. In the new model, these processes are implemented by allowing liquid water from rain and/or snowmelt, as prescribed by RACMO2 output, to exist in - and move through - the firn column. The amount of snow melt is removed from the top layer, and percolates down into the firn column. It refreezes when it reaches a firn layer with sufficient cold content $\left(T<0{ }^{\circ} \mathrm{C}\right)$ and pore space. To mimic capillary forces, a part of the liquid water remains in a layer that is at $0^{\circ} \mathrm{C}$. The maximum 


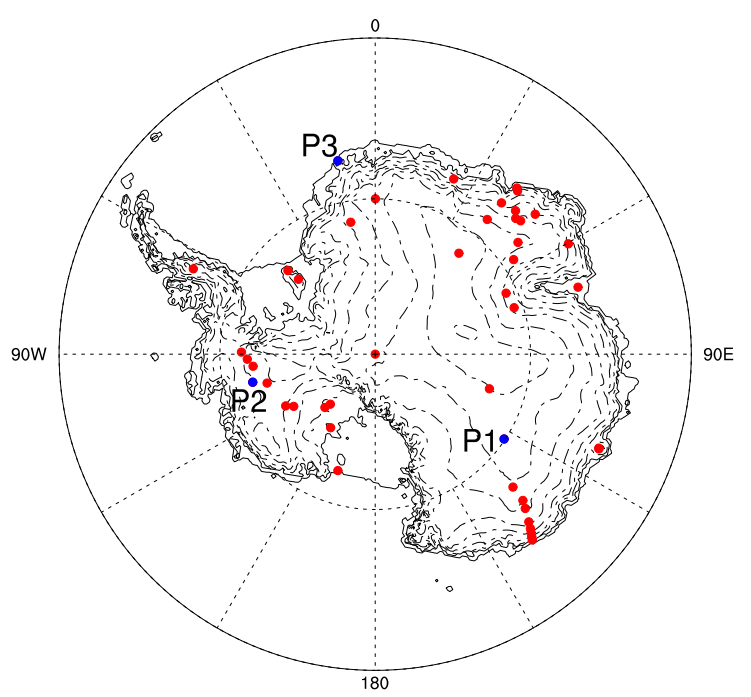

Fig. 2: Locations of 48 firn cores used in the model comparison in Sect. 2 (red and blue) and the locations of P1, P2 and P3, used in the analysis in Sect. 3.2 (blue).

amount of pore space used to store liquid water $\left(W_{\mathrm{mi}}\right.$ in $\left.\%\right)$ is taken as a function of the snow porosity $P$ (Coléou and Lesaffre, 1998):

$W_{\mathrm{mi}}=1.7+5.7\left(\frac{P}{(1-P)}\right)$

Typical values for $W_{\mathrm{mi}}$ are $9-13 \%$ close to the surface $\left(\rho=300-400 \mathrm{~kg} \mathrm{~m}^{-3}\right)$ and $4 \%$ lower in the firn column $(\rho$ $\left.\cong 650 \mathrm{~kg} \mathrm{~m}^{-3}\right)$. This retained water refreezes when the layer cools. By allowing water and therefore mass and heat to move through the firn column, the heat transport cannot be solved using an implicit numerical scheme, as in Helsen et al. (2008), but has to be solved explicitly, making the model computationally more expensive. The subsurface heat transport is simulated by using a one-dimensional time-dependent heat-transfer model (Paterson, 1994):

$\frac{\delta T}{\delta t}=k \frac{\delta^{2} T}{\delta z^{2}}$

where $k$ is the thermal diffusivity. This heat-transfer equation only contains a heat conduction term, where formally also heat advection and internal heating by deformation of ice should be included. However, the latter is small in the firn zone and therefore neglected, heat advection is implicitly taken into account by the downward motion of the firn layers at the speed of $v_{\text {ice }}$ (Helsen et al., 2008).

The initial density profile of the time-dependent simulation is obtained by spinning up the model as long as needed to refresh the entire firn layer. As the average annual accumulation and depth of the firn layer vary widely in space, the spin-up period is determined uniquely for every grid point. To obtain the input for the spin-up period, the 1979-2009 period is repeated into a time series long enough to refresh the entire firn layer. Hence, we assume this 31-year period is representative for the past 100-1000 years and the firn layer to be in steady state.

The previous model version used a densification expression adapted from Zwally and Li (2002), with a single densification expression for the complete density range. Various studies (Herron and Langway, 1980; Barnola et al., 1991) suggest one $\left(\rho \cong 550 \mathrm{~kg} \mathrm{~m}^{-3}\right)$ or even two $\left(\rho \cong 550 \mathrm{~kg} \mathrm{~m}^{-3}\right.$ and $\rho \cong 830 \mathrm{~kg} \mathrm{~m}^{-3}$ ) critical values to separate different densification processes that occur in the firn column. In the upper part $\left(\rho \leq 550 \mathrm{~kg} \mathrm{~m}^{-3}\right)$, the dominant densification processes are grain settling and packing of snow grains (Herron and Langway, 1980). Thereafter, densification is slower and mainly due to sublimation, diffusion and deformation processes until the density reaches the pore close-off depth $(\rho$ $\cong 830 \mathrm{~kg} \mathrm{~m}^{-3}$ ), where the remaining air bubbles get trapped in the ice. Further densification takes place by compression of these bubbles, until the density of glacier ice $(\rho \cong$ $917 \mathrm{~kg} \mathrm{~m}^{-3}$ ) is reached. Obviously, outside the dry snow zone refreezing of melt water and/or liquid precipitation also cause firn to densify.

Our FDM uses the dry snow densification expression proposed by Arthern et al. (2010) (Ar10 from now on) (Eq. 5). Ar10 use different densification expressions above and below the critical density value $\left(\rho=550 \mathrm{~kg} \mathrm{~m}^{-3}\right)$ and therefore are better able to capture the faster densification near the surface.

$\operatorname{Ar} 10 \mathrm{~T}: \frac{d \rho}{d t}=C \dot{b} \mathrm{~g}\left(\rho_{\mathrm{i}}-\rho\right) e^{\left(\frac{-E_{\mathrm{c}}}{R T_{\mathrm{S}}}+\frac{E_{\mathrm{g}}}{R T_{\mathrm{S}}}\right)}$

where $E_{\mathrm{c}}, E_{\mathrm{g}}$ and $C$ are constants, $\dot{b}$ is the average annual accumulation, $g$ the gravitational acceleration, $\rho_{\mathrm{i}}$ the ice density $\left(917 \mathrm{~kg} \mathrm{~m}^{-3}\right)$ and $R$ the gas constant and "T" in Ar10T refers to the time-dependent model version. Note that $C$ has different values above (0.03) and below (0.07) the critical density level $\rho=550 \mathrm{~kg} \mathrm{~m}^{-3}$. To convert Ar10T to a steady-state solution (Ar10S), the vertical displacement of a firn layer has to equal the average annual accumulation rate divided by the ice density. Also the local temperature $\left(T_{\mathrm{s}}\right)$ in the exponential term is replaced by the annual average surface temperature $\left(\bar{T}_{\mathrm{s}}\right)$ :

Ar10S: $\frac{d \rho}{d z}=C d z \rho \mathrm{g}\left(\rho_{\mathrm{i}}-\rho\right) e^{\left(\frac{-E_{\mathrm{c}}}{R \bar{T}_{\mathrm{S}}}+\frac{E_{\mathrm{g}}}{R T_{\mathrm{S}}}\right)}$

where $d z$ is the thickness of a firn layer in metres. Figure $3 \mathrm{a}$ compares firn density profiles from Eqs. 5 and 6 for a point in Marie Byrd Land (MBL), for which the climate characteristics are listed in Table 1. The oscillations in Ar10T are related to the strong non-linear dependence of densification rate on temperature. This effect is only present in the top few meters of the firn column, where the seasonal temperature 
Table 1: RACMO2/ANT climate characteristics of a point in Marie Byrd Land (MBL) and South Pole (SP): latitude, longitude, height above sea level, average annual temperature, accumulation, $10 \mathrm{~m}$ wind speed and melt over the 1979-2009 period.

\begin{tabular}{lccccccc}
\hline & Lat $\left({ }^{\circ} \mathrm{N}\right)$ & $\operatorname{Lon}\left({ }^{\circ} \mathrm{E}\right)$ & $h_{s}(\mathrm{~m})$ & $\overline{T_{S}}(\mathrm{~K})$ & $\dot{b}\left(\mathrm{~mm} \mathrm{yr}^{-1}\right)$ & $\overline{V_{10}}\left(\mathrm{~m} \mathrm{~s}^{-1}\right)$ & $\bar{M}\left(\mathrm{~mm} \mathrm{yr}^{-1}\right)$ \\
\hline MBL & -79.6 & -105.0 & 1912 & 241.0 & 306.0 & 6.64 & 0.0 \\
SP & -90.0 & 0.0 & 2797 & 220.3 & 56.0 & 5.55 & 0.0 \\
\hline
\end{tabular}
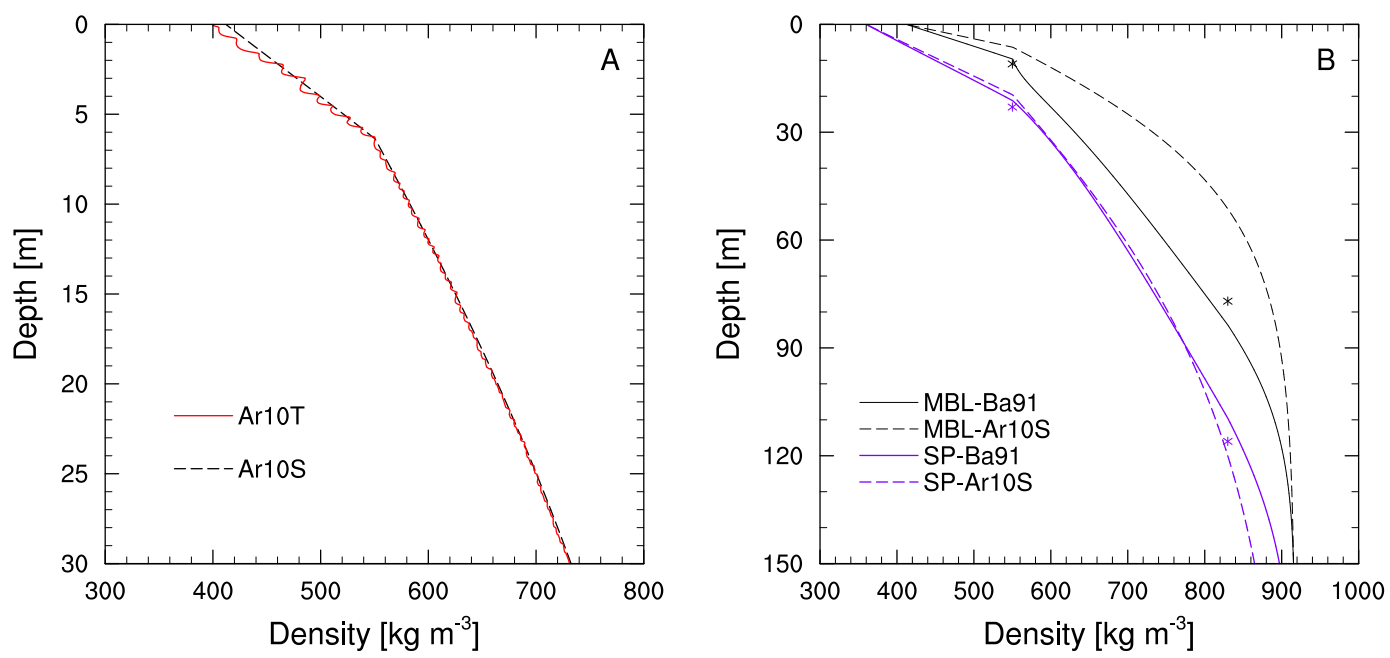

Fig. 3: Firn density profiles of the steady-state Ar10S and time-dependent Ar10T densification expressions for a location in Marie Byrd Land (A) and steady-state density profiles of Ar10S and Ba91, with the observed $z_{550}$ and $z_{830}$ (B) for South Pole (purple) and the MBL location as in Fig. A (black). Climatic characteristics of both points are listed in Table 1.

cycle is significant. To compensate for this systematic bias and to enable a comparison with other steady-state models, an offset is applied to the surface density in the steady-state model, so that the critical $\rho=550 \mathrm{~kg} \mathrm{~m}^{-3}$ level occurs at the same depth in both solutions.

\subsection{Model performance and tuning}

We compared the modelled depths of the critical density values $\rho=550 \mathrm{~kg} \mathrm{~m}^{-3}\left(z_{550}\right)$ and $\rho=830 \mathrm{~kg} \mathrm{~m}^{-3}$ (z.830) with observations from 48 ice core drilling sites in Antarctica (Fig. 2) (van den Broeke, 2008). We also compare the results of the steady-state model to van den Broeke (2008), who used the steady-state expressions of Barnola et al. (1991):

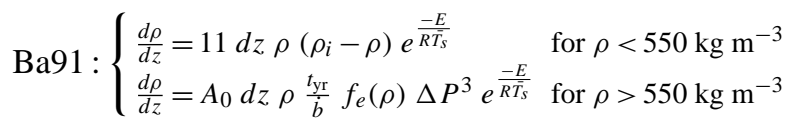

where $E$ and $A_{0}$ are constants, $t_{\mathrm{yr}}$ is the number of seconds in a year and $\Delta P$ the overburden pressure. Figure $3 \mathrm{~b}$ compares the density profiles of Eqs. 6 and 7 with the observed $z_{550}$ and $z_{830}$ at South Pole and MBL (climate characteristics are listed in Table 1). Although the densification expressions are quite different, the results for South Pole are similar and both correspond rather well with the observed depths. For the MBL point, Ba91again shows good agreement with the observed depths, while Ar10S densifies too quickly and simulates too shallow critical depths. Around $15 \mathrm{~m}$ in the Ba91 simulation a numerical artifact is visible, caused by the overburden pressure $\Delta P$ in Eq. 7. The densification rate is underestimated at these low depths since there is not enough overburden pressure in the above layers. However, Ba91 simulates the depths of the critical levels quite well.

Figure 4 compares observed and modelled $z_{550}$ and $z_{830}$ for all 48 observation locations. In order to isolate $z 830$ from processes above $z_{550}$, we used $z_{830}^{*}=z_{830}-z_{550}$. Almost everywhere, Ar10S causes the firn to densify too quickly in the upper part of the firn column and therefore under-predicts z550. The same pattern is observed for the points with a relatively small $z_{830}$, with deviations up to $50 \%$. However, for points with larger $z 830$ the pattern is reversed. The Ba91 results are very similar to those of van den Broeke (2008), in which a previous RACMO2/ANT dataset (van de Berg et al., 2006) was used.

The ratio of modelled to observed depths (MO) in Ar10S is found to be highly correlated with average annual accumulation at the 48 core sites, both for $z_{550}$ and $z_{830}$ (Fig. 5). The correlation is such that the effect of the average annual accumulation $\dot{b}$ on the densification rate is too large. This also explains the agreement of Ar10S with observations in 

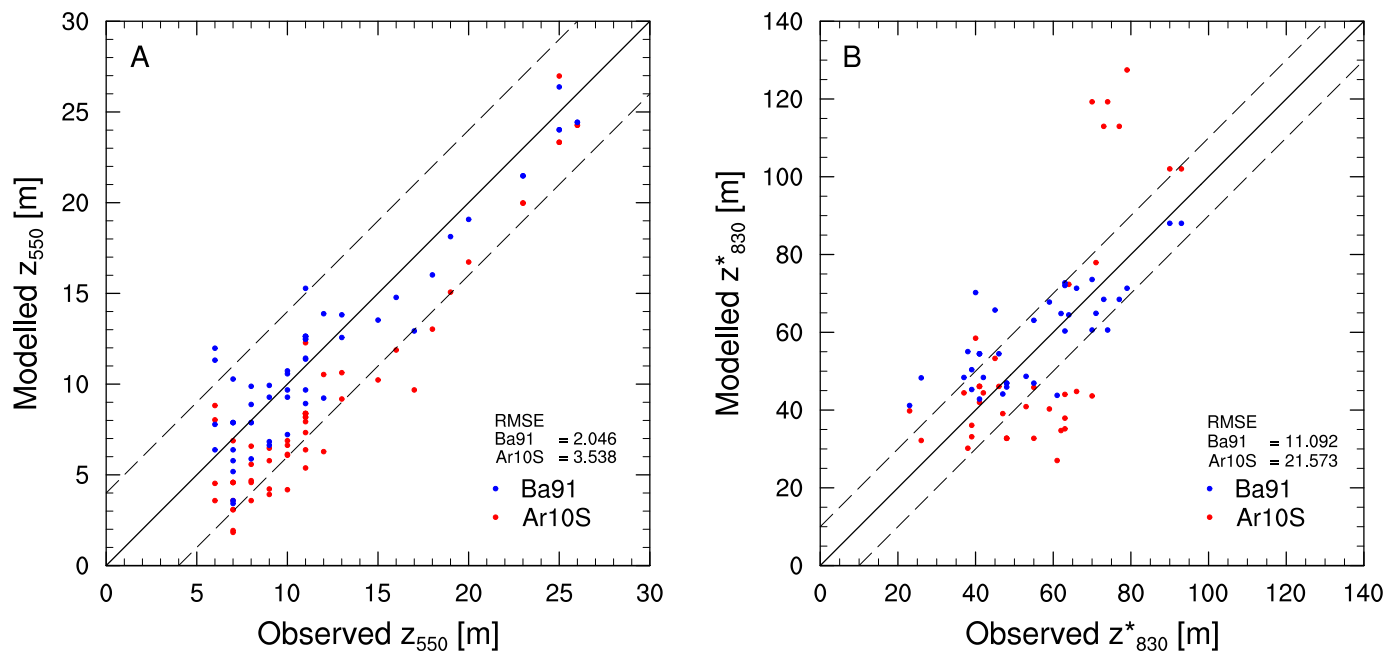

Fig. 4: Modelled vs observed depth of the $\rho=550 \mathrm{~kg} \mathrm{~m}^{-3}$ (A) and $\rho=830 \mathrm{~kg} \mathrm{~m}^{-3}$ (B) levels, for the densification expressions of Ar10S and Ba91.
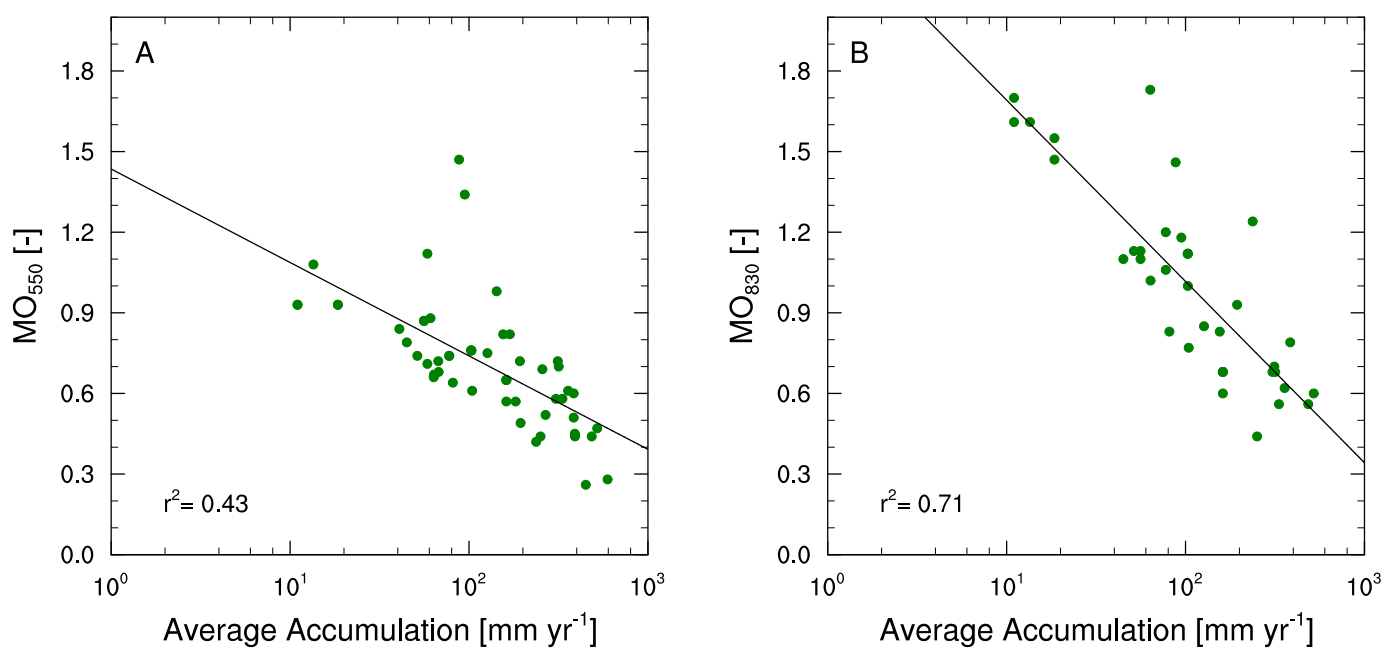

Fig. 5: MO-ratio of Ar10S for $z_{550}(\mathbf{A})$ and $z_{830}^{*}$ (B) vs. the average annual accumulation, the regression line equations are listed in Eq. 8 and 9.

Fig. 3b at South Pole, where low average annual accumulation leads to a MO-ratio close to 1 . The higher average annual accumulation at MBL in Fig $3 b$ on the other hand, leads to a MO-ratio $<1$ and thereby shows an overestimated densification rate in Ar10S. Previously, Herron and Langway (1980) proposed the exponent $\alpha$ in $\dot{b}^{\alpha}$ to be chosen between 0.5 and 1.1. However, Zwally and Li (2002) and Helsen et al. (2008) later assumed $\alpha=1$. To introduce the correct accumulation dependence, we multiply the densification expressions of Ar10S with the relations of the regressions in Fig. 5, being:

$$
\begin{array}{ll}
\mathrm{MO}_{550}=1.435-0.151 \ln (\dot{b}) & \text { for } \rho<550 \mathrm{kgm}^{-3} \\
\mathrm{MO}_{830}=2.366-0.293 \ln (\dot{b}) & \text { for } \rho>550 \mathrm{kgm}^{-3}
\end{array}
$$

For extreme average annual accumulation values $(\dot{b}>$ $\left.3213 \mathrm{~mm} \mathrm{yr}^{-1}\right), \mathrm{MO}_{830}$ becomes negative, which occurs on a few points in the Antarctic Peninsula. $\mathrm{MO}_{550}=0$ is not reached for realistic values of $\dot{b}$. We impose a minimum value of 0.25 on $\mathrm{MO}_{550}$ and $\mathrm{MO}_{830}$, corresponding roughly to areas where the average annual accumulation exceeds $1400 \mathrm{~mm} \mathrm{yr}^{-1}$. Figure 6 compares the observed to the updated model values of $z_{550}$ and $z_{830}$. For both critical depths, the agreement of the steady-state FDM with the observations is now comparable to $\mathrm{Ba} 91$, but the great advantage of the new expression is that it can also be used in a time-dependent fashion. 

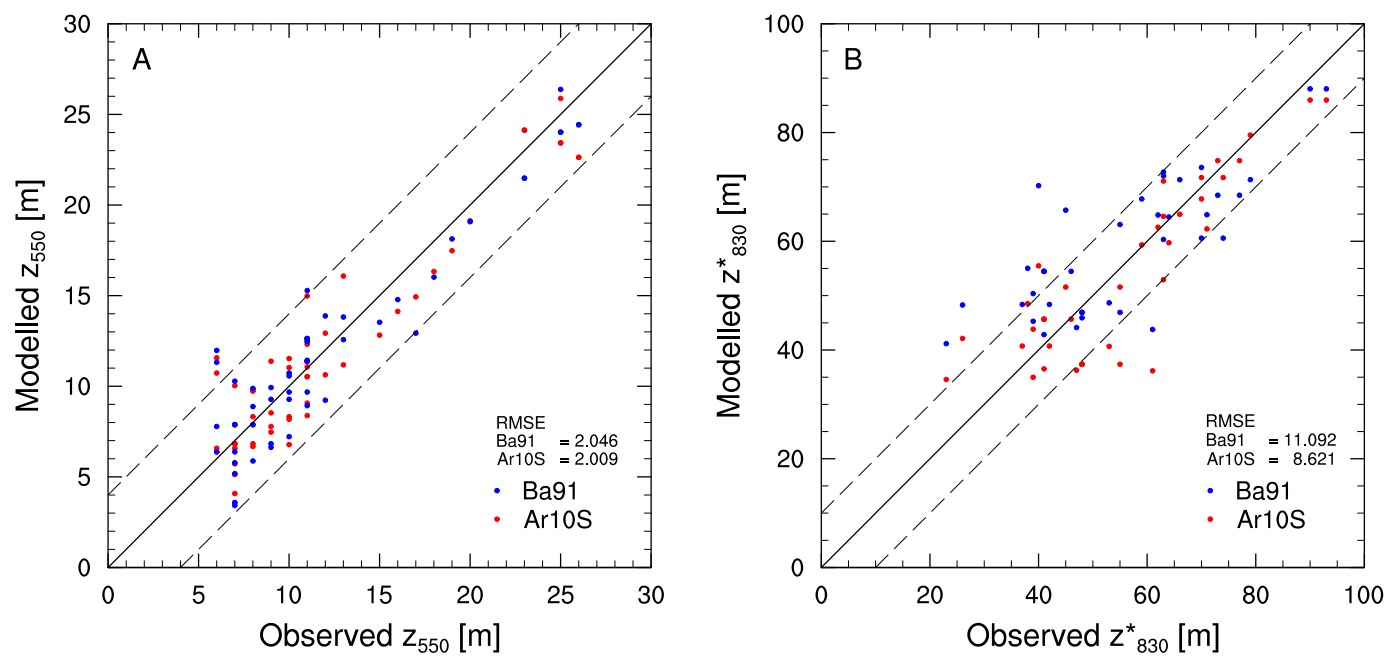

Fig. 6: Modelled vs observed depth of the $\rho=550 \mathrm{~kg} \mathrm{~m}^{-3}$ (A) and $\rho=830 \mathrm{~kg} \mathrm{~m}^{-3}$ (B) levels, for the updated densification expressions of Ar10S and Ba91.

\section{Applications}

\subsection{Steady-state Antarctic firn density profiles}

The steady-state expression forced by average RACMO2/ANT climate fields of average annual accumulation, surface temperature and wind speed, enables us to look at the spatial variability of the characteristics of the Antarctic firn column (Fig. 7 and 8). Since the resolution of RACMO2/ANT output has increased from 55 to $27 \mathrm{~km}$, we see much more detail than in van den Broeke (2008). The modelled density of the surface snow is shown in Fig. 7a and shows a typical distribution of relatively low density surface snow in the East Antarctic interior $\left(300-340 \mathrm{~kg} \mathrm{~m}^{-3}\right)$, and high densities along the ice sheet margin $\left(420-460 \mathrm{~kg} \mathrm{~m}^{-3}\right)$, where temperature, precipitation and wind speeds are high. The two large ice shelves have a slightly lower surface density than other coastal regions because, in absence of orographic forcing, the average annual accumulation is relatively small. Along the West Antarctic coast and in the Antarctic Peninsula, the highest surface density values occur, forced by a combination of high temperatures, wind speeds and precipitation rates.

The points without values in Figs. 7 and 8 are regions where, according to RACMO2/ANT, no stable firn layer can exist as average annual accumulation (1979-2009) is exceeded by either sublimation or melt. The location of these so called blue ice areas correspond reasonably well to the areas presented in Winther et al. (2001). Wind-induced blue ice areas occur in the vicinity of the Lambert Glacier and along the eastern border of the Transantarctic Mountains. On Larsen C Ice Shelf, snow melt exceeds precipitation in RACMO2/ANT, so no long-term firn layer can build up. As Larsen $\mathrm{C}$ is currently covered by a significant layer of firn (Holland et al., 2011), it is likely that the present firn

layer was formed before the recent warming of the Antarctic Peninsula (Vaughan et al., 2003) and is now slowly degrading.

Figure $7 \mathrm{~b}-\mathrm{c}$ show the spatial distribution of two critical depths in the firn column; $z_{550}$ and $z_{830}$. These fields show roughly the inverse pattern of surface density. This is especially valid for $z 550$ as the surface density (ranging from $300 \mathrm{~kg} \mathrm{~m}^{-3}$ to $450 \mathrm{~kg} \mathrm{~m}^{-3}$ ) determines the start of the density-depth profile. The highest values of $z_{550}$ and $z_{830}$ are found in the interior of East Antarctica with smaller values in the coastal regions. In West Antarctica and the Antarctic Peninsula the pattern is somewhat different; while $z 550$ is small, $z_{830}$ shows relatively high values. This is caused by the high average annual accumulation values in these regions; the fast burial of fresh snow leads to a slow densification with depth. The thickness of the firn column in Antarctica, taken as $z 830$, is only $40-50 \mathrm{~m}$ around and on the big ice shelves (Ross Ice Shelf, Filchner Ronne Ice Shelf and the Amery Ice Shelf). Here, a combination of relatively high temperatures and relatively low precipitation amounts cause a rapid densification of firn with depth. The highest values are found on top of the East Antarctic plateau with values just reaching $120 \mathrm{~m}$.

An important quantity is the amount of air in the firn column. The thickness change resulting from compressing the whole firn column until it has ice density gives the length of the firn air column. Figure 8a shows the spatial distribution of the length of this firn air column. It resembles the depth of the firn layer in Fig. 7c, indicating that deeper firn columns generally contain more air than shallow columns. This is supported by the average density of the firn column, which shows little variability; values range between $650 \mathrm{~kg} \mathrm{~m}^{-3}$ on the East Antarctic plateau and $690 \mathrm{~kg} \mathrm{~m}^{-3}$ along the edges of the ice sheet (not shown). In other words, a deeper firn 


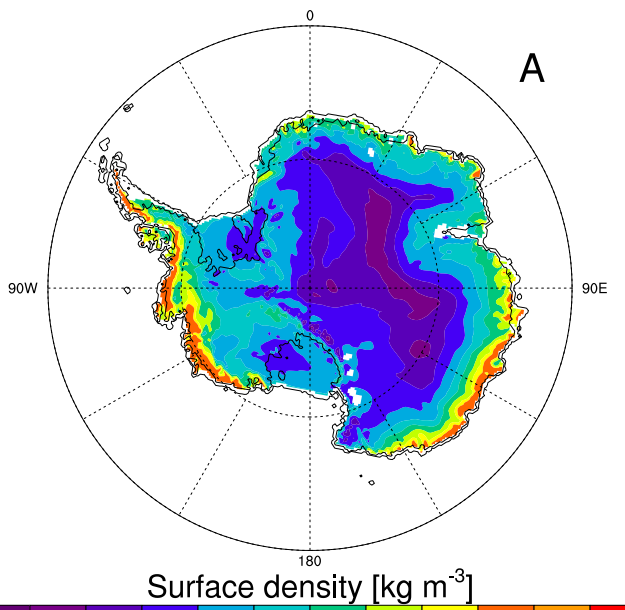

$\begin{array}{lllllllllll}300 & 320 & 340 & 360 & 380 & 400 & 420 & 440 & 460 & 480 & 500\end{array}$
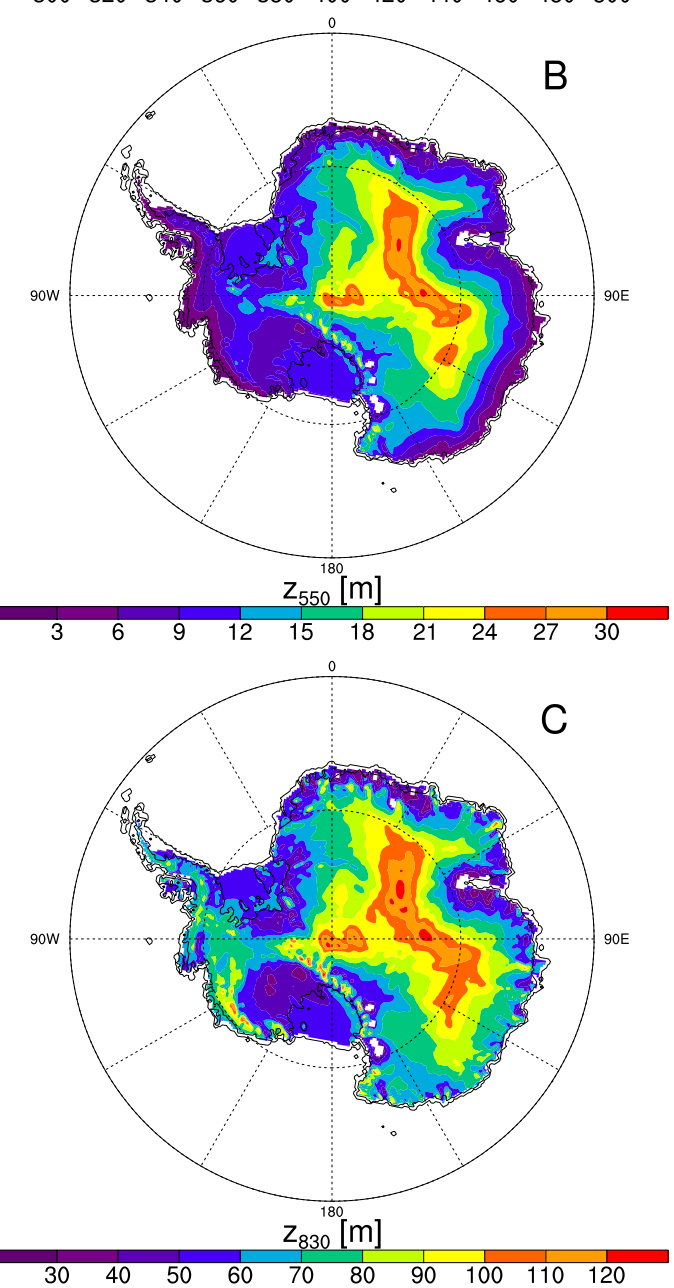

Fig. 7: Modelled surface density (A) and depths of the critical density levels $\rho=550 \mathrm{~kg} \mathrm{~m}^{-3}$ (B) and $\rho=830 \mathrm{~kg} \mathrm{~m}^{-3}$ (C).

column is not necessarily denser, and will contain more air. On average there is $22.6 \mathrm{~m}$ air in the firn column (Fig 8a), but the modelled range of values is large $(10-40 \mathrm{~m})$ due the pre- viously mentioned climatic differences between the coastal regions and the interior. The average thickness of the Antarctic ice sheet is $2.06 \mathrm{~km}$ (Lythe et al., 2001), so on average a correction of just over $1 \%$ has to be applied to get the total mass of the ice sheet. However, ice thicknesses are smaller near the coast; here, the firn air correction can be significant, especially when it is used to derive ice thickness of floating glacier tongues, using surface elevation in combination with a floatation criterium (van den Broeke et al. (2008); Rignot et al. (2008)). Figure $8 \mathrm{~b}$ expresses the air thickness as a percentage of the total ice column. On the ice shelves and in coastal and mountainous areas, values of 7-9\% are found. White areas indicate ice thicknesses (Lythe et al., 2001) that are shallower than the modelled firn-ice transition depths.

\subsection{Time-dependent firn density and surface elevation}

The new densification expressions can also be used in the time-dependent FDM. By forcing the time-dependent FDM with climate model time series, we obtain the evolution of the surface height with time and are able to study the individual processes that contribute to the vertical movement of the surface. Fig. 9a-c shows the seasonal cycle of the surface velocity components and Fig. 9d-f the resulting surface elevation evolution, i.e. the integrated signal of $v_{\text {tot }}$ in Fig. 9ac, for three locations on the AIS (Fig. 2): P1 is located in the cold and dry East Antarctic interior, P2 is in wetter and warmer West Antarctica and P3 in coastal Dronning Maud Land where melt occurs annually. The climate characteristics of these points are shown in Table 2.

The average seasonal cycle is similar for the three locations, with upward motion of the surface (positive $v_{\text {tot }}$ ) in autumn, winter and spring and a relatively strong downward motion (negative $v_{\text {tot }}$ ) in summer. At all three locations, $v_{\text {ice }}$ is constant throughout the year, as it is assumed proportional to the average annual accumulation. At P1 and P2, no melt occurs $\left(v_{\text {me }}=0\right)$, hence the seasonal variations are determined by accumulation and firn densification. The strong non-linear temperature dependence of the latter causes a densification peak in summer. In combination with a summer minimum in $v_{\text {acc }}$, this causes the summer lowering of the surface. The contribution of firn densification to the vertical movement of the surface is relatively constant from year to year, as only the upper few meters of the firn layer experience significant annual temperature changes. So, at P1 and $\mathrm{P} 2$, the variations in $v_{\text {total }}$ are mainly caused by variability in snowfall.

At P3, melt mainly occurs in December and January, which lowers the surface significantly. In combination with the variability in accumulation, this leads to a relatively large inter-annual variability for the summer months. Interestingly, the contribution to surface lowering by firn densification is almost three times smaller at P3 than at P2. One reason is the presence of refrozen meltwater in the firn column at P3, which causes higher average firn densities and therefore 

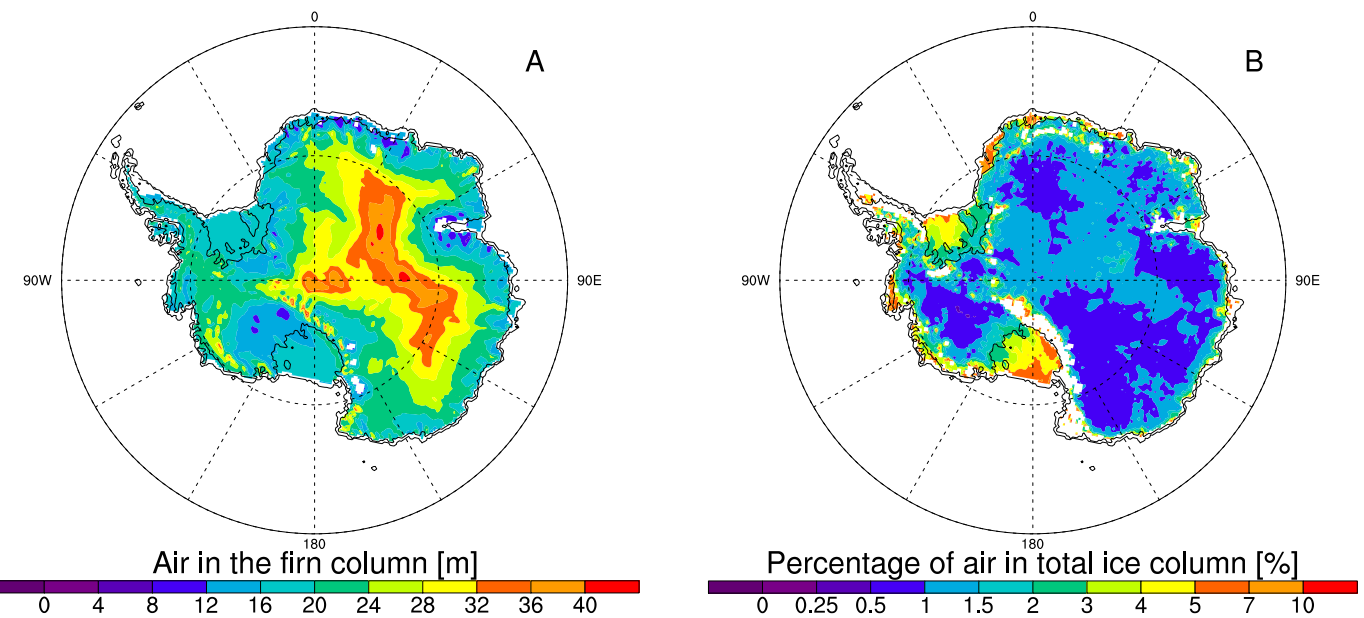

Fig. 8: The modelled amount of air in the firn column, expressed as the firn correction in $\mathrm{m}(\mathbf{A})$ and as a fraction of the total thickness of the ice in \% (B).
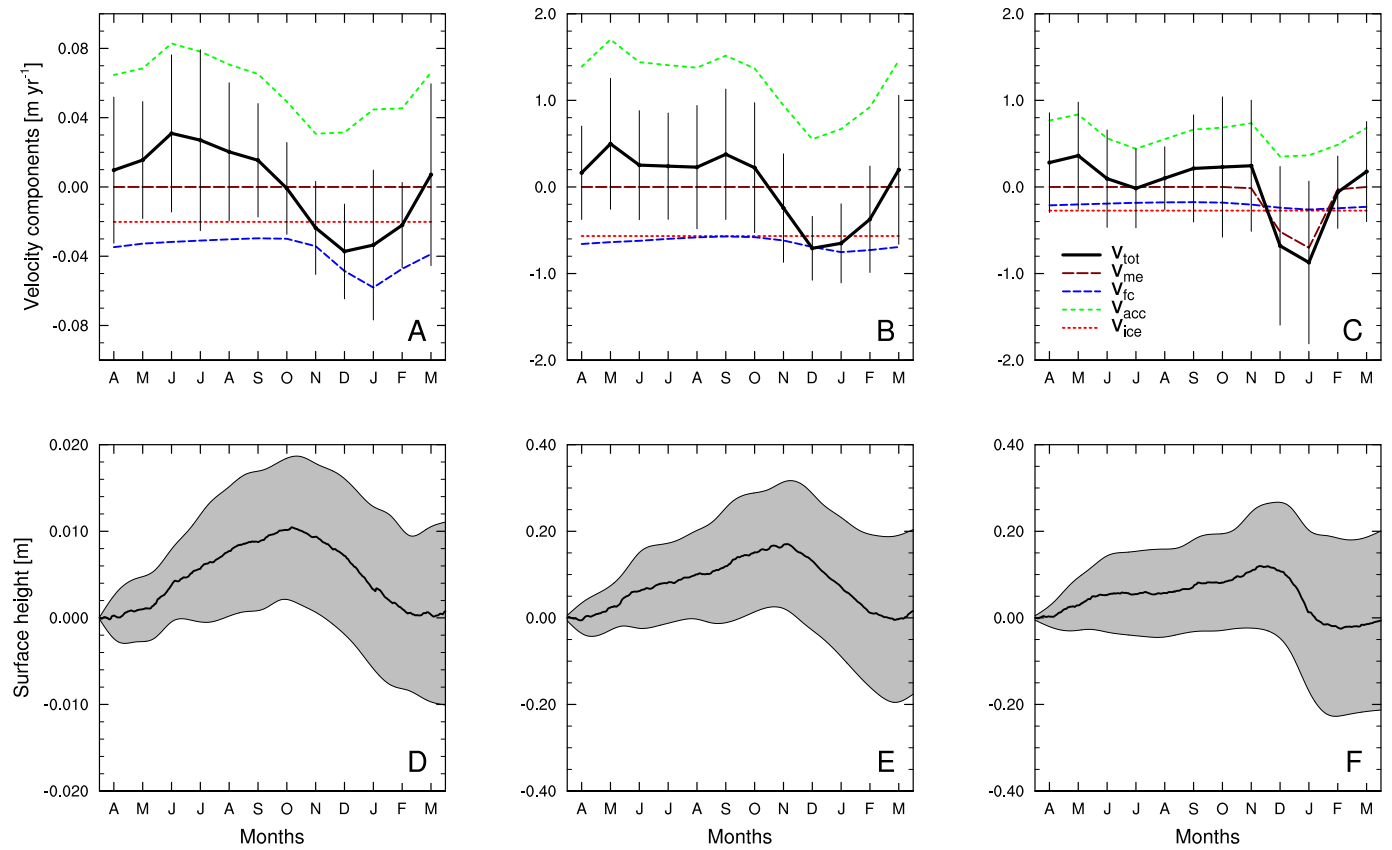

Fig. 9: The monthly averaged (1979-2009) velocity components that determine the vertical displacement of the surface: $v_{\text {acc }}$, $v_{\text {me }}, v_{\text {fc }}, v_{\text {ice }}$ and $v_{\text {tot }}(\mathbf{A}, \mathbf{B}, \mathbf{C})$ and the daily averaged (1979-2009) surface height and standard deviation (D, E, F) for P1, P2 and P3 (see Fig. 2). Note the different scales.

limits the potential total firn densification. Also, the firn layer at $\mathrm{P} 2$ is much deeper than at $\mathrm{P} 3$, due to the higher average annual accumulation amounts.

Figure 10 shows the surface height evolution for the entire 31-year period (1979-2009) at P2 and P3. The evolution of the surface height in P1 shows small inter-annual variability and is therefore not included. For P2 and P3, the inter-annual variability as discussed above is visible as decadal trends. At $\mathrm{P} 2$, inter-annual variability is almost completely caused by accumulation variability where wetter (e.g. 2005-2006) and dryer (e.g. 1988-1991) than average periods cause upward or downward trends in surface height. An interesting asymmetry is visible: the lowering at $\mathrm{P} 2$ is more gentle than in $\mathrm{P} 3$, as firn densification is a slow, but steady process compared to melt. At P3, the more rapid lowering of the surface is often caused by strong melt seasons in combination with less than average precipitation (e.g. 1981-1983), while upward motions are associated with wetter periods in combination with a weak melt season (e.g. 2008-2009). 
Table 2: RACMO2/ANT climate characteristics of points P1, P2 and P3: latitude, longitude, height above sea level, average annual temperature, accumulation, $10 \mathrm{~m}$ wind speed and melt over the 1979-2009 period.

\begin{tabular}{cccccccc}
\hline & Lat $\left({ }^{\circ} \mathrm{N}\right)$ & Lon $\left({ }^{\circ} \mathrm{E}\right)$ & $h_{s}(\mathrm{~m})$ & $\overline{T_{s}}(\mathrm{~K})$ & $\dot{b}\left(\mathrm{~mm} \mathrm{yr}^{-1}\right)$ & $\overline{V_{10}\left(\mathrm{~m} \mathrm{~s}^{-1}\right)}$ & $\bar{M}\left(\mathrm{~mm} \mathrm{yr}^{-1}\right)$ \\
\hline P1 & -75.1 & 123.4 & 3262 & 218.0 & 18.5 & 5.14 & 0.0 \\
P2 & -77.8 & -102.9 & 1392 & 245.6 & 520.4 & 7.14 & 0.0 \\
P3 & -71.1 & -10.9 & 40 & 255.7 & 251.0 & 8.26 & 53.2 \\
\hline
\end{tabular}

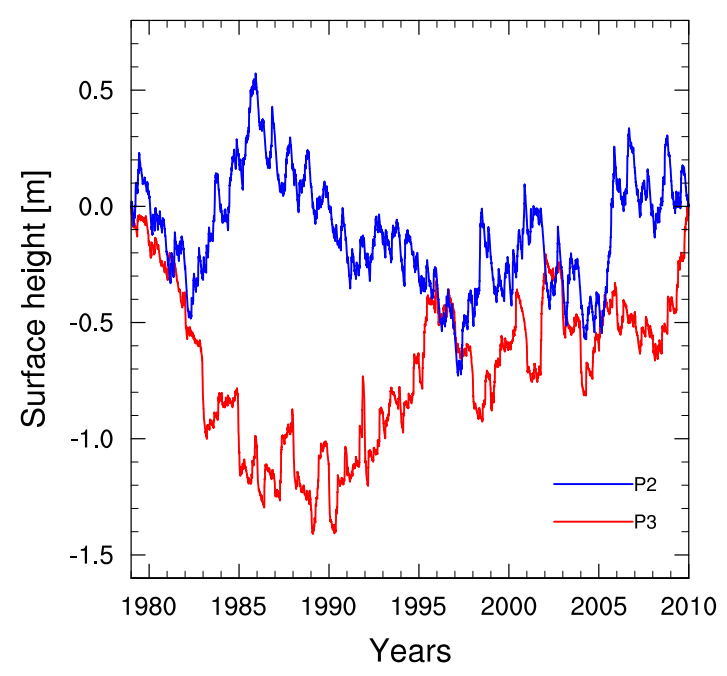

Fig. 10: Surface height evolution (1979-2009) for P2 and P3 (see Fig. 2).

\section{Summary and conclusions}

After introducing an accumulation dependence into the Ar10 densification expression, good agreement is found with 48 steady-state firn profiles from the Antarctic ice sheet. The steady-state version of the new densification expression produces results comparable to the steady-state solution of Barnola et al. (1991). A great advantage of the updated expression is that it can also be used in time-dependent mode. Moreover, by introducing liquid water into the model, it can now be applied to the entire Antarctic ice sheet including its floating ice shelves, as long as the surface mass balance is positive and a firn layer can build up.

Several improvements to the model can be made. The accumulation dependence that has been introduced in the densification expression of Arthern et al. (2010) is tuned and validated with the same dataset of 48 Antarctic firn cores. Ideally, a part of the dataset should be used for tuning and another part for validation. However, the Antarctic climate is very diverse and some climate zones are only represented by a few points, so splitting the dataset of only 48 firn cores is no option at present. The time-dependent model can at present not be validated with observations, as long-term reliable surface height measurements at high temporal resolution are scarce. Satellite height measurements do not have the right time resolution and are often very noisy, while insitu observations typically span less than a year. Moreover, to perform a thorough comparison with in-situ observations, the height measuring instrument should be fixed at a reference level outside the firn layer, which is virtually impossible.

This is also the reason for choosing to improve a semiempirical model instead of using a more physically-based firn densification model. The physics of firn densification are still not fully understood and mainly observed in laboratories. This explains our choice for an empirical model that describes firn densification in relation to temperature and accumulation.

The fresh snow density parameterization of Kaspers et al. (2004) is now used in both the steady state and the timedependent firn densification model. As the density of fresh snow is most likely not constant in time, this could be a point of improvement in future research of the time-dependent model. However, almost no observations on Antarctic fresh snow density are available: most observations are averaged over the first $0.5-1 \mathrm{~m}$.

In steady-state mode, the FDM is used to assess the spatially variable characteristics of the Antarctic firn layer. On the cold and dry East Antarctic plateau, the lowest surface snow density and deepest firn-ice transitions are found. Moving towards the coastal areas the climate gets warmer, wetter and windier, causing the surface density to increase and the firn layer depth to decrease. Some regions do not obey this general pattern, e.g. the coast of West Antarctica shows high surface densities and small values of the depth of the $\rho=550 \mathrm{~kg} \mathrm{~m}^{-3}$ level (z550), but deep firn-ice transition depths $\left(z_{830}\right)$, reaching $120 \mathrm{~m}$. The high average annual accumulation rate induces a fast burial of firn, which leads to small gradients in firn density with depth. The same effect occurs along the Antarctic mountain ranges, but is less evident and only present in some isolated spots.

Steady-state profiles can be used to quantify the amount of air in the firn column, a quantity needed to convert ice thickness to total ice mass. The firn correction averaged over the entire ice sheet is small (1\%), but along mountain ranges and especially on ice shelves, the values go up to $9 \%$. This constitutes a significant correction for ice flux calculations at 
the grounding line (e.g. Rignot et al., 2008). The spatial variability of firn layer characteristics resembles that presented by van den Broeke (2008), but with much improved horizontal resolution.

The effect of melt is not included in the steady-state profiles: if melt occurs, meltwater refreezes deeper in the firn column resulting in layers with higher density and/or complete ice lenses. In a steady-state profile these features cannot be modelled, as they move to greater depths with time. On average, the density will be higher due to this refrozen water. As heat is released upon refreezing, the local firn temperature will increase, further accelerating the densification. On the other hand, ice layers lead to a higher average density, which in turn decreases the potential densification rate.

The time-dependent version of the FDM is used to study the evolution of the surface height and firn density in time and depth. It shows that within three different climatic zones in Antarctica, the surface elevation has a clear annual cycle with upward motion in austral autumn, winter and spring due to accumulation and relatively slow firn compaction, and a lowering in summer when accumulation is lower and firn densification is more rapid in response to higher temperatures. If melt is present, the lowering of the surface in summer is even more pronounced. In the interior of Antarctica, the year-to-year surface elevation variability is almost completely caused by the variability in accumulation, while in melt areas the strength of the melt season is also important. Firn densification rate shows less year-to-year variability.

Acknowledgements. This work was supported by funding from the ice2sea programme from the European Union 7th Framework Programme, grant number 226375. Ice2sea contribution number 055 .

Edited by: I. M. Howat

\section{References}

Arthern, R. J., Vaughan, D. G., Rankin, A. M., Mulvaney, R., and Thomas, E. R.: In situ measurements of Antarctic snow compaction compared with predictions of models, J. Geophys. Res., 115, (F03011), doi:10.1029/2009JF001306, 2010.

Barnola, J.-M., Pimienta, P., Raynaud, D., and Korotkevich, Y. S.: $\mathrm{CO}_{2}$-climate relationship as deduced from the Vostok ice core: a re-examination based on new measurements and on a reevaluation of the air dating, Tellus, 43B, 83-90, 1991.

Coléou, C. and Lesaffre, B.: Irreducible water saturation in snow: experimental results in a cold laboratory, Ann. Glaciol., 26, 6468, 1998.

Davis, C. H., Li, Y., McConnell, J. R., Frey, M. M., and Hanna, E.: Snowfall-driven growth in East Antarctic ice sheet mitigates recent sea-level rise, Science, 308, 1898-1901, doi:10.1126/science.1110662, 2005 .

Helsen, M., M. R. van den Broeke, R. S. W. van de Wal, W. J. van de Berg, E. van Meijgaard, C. H. Davis, Y. Li, and
I. Goodwin (2008), Elevation changes in Antarctica mainly determined by accumulation variability, Science, 320, 1626-1628, doi:10.1126/science.1153894.

Herron, M. and Langway, C.:Firn densification: an empirical model, J. Glaciol., 25, 373-385, 1980.

Holland, P. R., Corr, H. F. J., Pritchard, H. D., Vaughan, D. G., Arthern, R. J., Jenkins, A., and Tedesco, M.: The air content of Larsen C ice shelf, Geophys. Res. Lett., 38, L10503, doi:10.1029/2011GL047245, 2011.

Kaspers, K. A., van de Wal, R. S. W., van den Broeke, M. R., Schwander, J., van Lipzig, N. P. M., and Brenninkmeijer, C. A. M.: Model calculations of the age of firn air across the Antarctic continent, Atmos. Chem. Phys. Discuss., 4, 18171853, doi:10.5194/acpd-4-1817-2004, 2004.

Kuipers Munneke, P., van den Broeke, M. R., Lenaerts, J. T. M., Flanner, M. G., Gardner, A. S., and van de Berg, W. J.: A new albedo parameterization for use in climate models over the Antarctic ice sheet, J. Geophys. Res., 116, D05114, doi:10.1029/2010JD015113, 2011.

Lenaerts, J. T. M. and van den Broeke, M. R.: Modeling snowdrift in Antarctica with a regional climate model, Part II: Results, J. Geophys. Res., in review, 2011.

Lenaerts, J. T. M., van den Broeke, M. R., van de Berg, W. J., van Meijgaard, E., and Munneke, P. K.: A new, high resolution surface mass balance map of antarctica (1979-2009) based on regional climate modeling, Geophys. Res. Lett., in review, (2011a).

Lenaerts, J. T. M., van den Broeke, M. R., Déry, S. J., van Meijgaard, E., van de Berg, W. J., Palm, S. P., and Rodrigo, J. S.: Modeling snowdrift in Antarctica with a regional climate model, Part I: Methods and model evaluation, J. Geophys. Res., in review, (2011b).

Li, J. and Zwally, H. J.: Modeling the density variation in the shallow firn layer, Ann. Glaciol., 38, 303-313, 2004.

Lythe, M. B., Vaughan, D. G., and the BEDMAP Consortium BEDMAP: A new ice thickness and subglacial topographic model of Antarctica, J. Geophys. Res., 106, 11335-11352, doi:10.1029/2000JB900449, 2001.

McConnell, J. R., Arthern, R. J., Mosley-Thompson, E., Davis, C. H., Bales, R. C., Thomas, R., Burkhart, J. F., and Kyne, J. D.: Changes in Greenland ice sheet elevation attributed primarily to snow accumulation variability, Nature, 406, 877-879, 2000.

Paterson, W. S. B.:The physics of glaciers, 3 Edn., Pergamon, 1994.

Pimienta, M. and Duval, P.: Rate controlling processes in the creep of polar glacier ice, J. Phys., 48, 243-248, 1987.

Rignot, E., Bamber, J. L., van den Broeke, M. R., Davis, C., Li, Y., van de Berg, W. J., and van Meijgaard, E.: Recent Antarctic ice mass loss from radar interferometry and regional climate modelling, Nat. Geosci., 1, 106-110, doi:10.1038/ngeo102, 2008.

van de Berg, W. J., van den Broeke, M. R., Reijmer, C. H., and van Meijgaard, E.: Reassessment of the Antarctic surface mass balance using calibrated output of a regional atmospheric climate model, J. Geophys. Res., 111, (D11104), doi:10.1029/2005JD006495, 2006.

van den Broeke, M. R.: Depth and density of the Antarctic firn layer, Arctic, Antarct. Alp. Res., 40, 432-438, doi:10.1657/1523-0430(07-021)[BROEKE]2.0.CO;2, 2008.

van den Broeke, M. R., van de Berg, W. J., and van Meijgaard, E.: Firn depth correction along the Antarctic grounding line, Antarct. Sci., 20, 513-517, doi:10.1017/S095410200800148X, 2008. 
Vaughan, D. G., Marshall, G. J., Connolley, W. M., Parkinson, C., Mulvaney, R., Hodgson, D. A., King, J. C., Pudsey, C. J., and Turner, J.: Recent rapid regional climate warming on the Antarctic Peninsula, Clim. Change, 60(3), 243-274, doi:10.1023/A:1026021217991, 2003.

Wilkinson, D. S.: A pressure-sintering model for the densification of polar firn and glacier ice, J. Glaciol., 34, 40-45, 1988.

Wingham, D. J., Wallis, D. W., and Sheperd, A.: Spatial and temporal evolution of Pine Island Glacier thinning, Geophys. Res. Lett., 36, L17501, doi:10.1029/2009GL039126, 2009.
Winther, J.-G., Jespersen, M. N., and Liston, G. E.: Blue-ice areas in Antarctica derived from NOAA AVHRR satellite data, J. Glaciol., 47, 325-334, 2001.

Zwally, H. J. and Li, J.: Seasonal and interannual variations of firn densification and ice-sheet surface elevation at the Greenland Summit, J. Glaciol., 48, 199-207, doi:10.3189/172756502781831403, 2002. 